\title{
International Outlook and Conclusions
}

After developing an instrument for measuring climate-relevant behaviors, considering the factors that shape these behaviors as well as their determinants and obstacles in the Austrian context, this final chapter ${ }^{1}$ discusses the same issues at an international level. It starts with an overview of the 2020 ISSP (International Social Survey Programme) questionnaire, which includes new questions related to housing, mobility, and diet. The ISSP fieldwork, however, is delayed due to the COVID-19 crisis, and we thus use data from the ECHOES project (Reichl et al., 2019) to show that our models also apply to other European countries. The section on the questionnaire development is followed by an analysis showing the different lifestyles from Chap. 6 at an international level and a brief consideration of the effects of the COVID-19 crisis on environmental attitudes and concerns. The analysis of the lifestyles shows that they can be found in other European countries as well. As for the COVID-19 crisis, we find a positive association between worries about COVID-19 and environmental attitudes. Yet, it is too early to assess if the pandemic has altered environmental concerns and behaviors permanently. The chapter concludes with a few final remarks.

\footnotetext{
${ }^{1}$ Lead author: Markus Hadler.
}

(C) The Author(s) 2022 


\subsection{International Surveys and Explained Variance}

The previous chapters discussed the development of valid and reliable measures for climate-relevant behaviors in the Austrian context. The work associated with the development of these questions also informed the development of the International Social Survey Programme's (www.issp. org) 2020 Environmental Attitudes and Behavior questionnaire. The development of all ISSP questionnaires is led by a drafting group, which reviews current literature, proposes different questions to the general assembly, and also conducts pre-tests with the proposed items. The 2020 drafting group was convened by the Austrian representatives Markus Hadler and Markus Schweighart. The other members were the ISSP representatives from Chile, Spain, Sweden, and Taiwan, as well as the two external experts Malcolm Fairbrother and Axel Franzen. The final adoption of all questions took place in a democratic process during the 2019 ISSP meeting, in which all member countries have a single vote.

The final questionnaire includes 60 questions on environmental attitudes and behaviors and an additional comprehensive set of variables on socio-demographics. As for climate-relevant behaviors, items on transportation, housing, and food were included. The exact items are:

(a) "In the last twelve months, how many trips did you make by plane? Count outward and return journeys, including transfers, as one trip."

(b) "In a typical week, about how many hours do you spend in a car or another motor vehicle, including motorcycles, trucks, and vans, but not counting public transport? Do not include shared rides in buses, minibuses, and collective taxis."

(c) "In a typical week, on how many days do you eat beef, lamb, or products that contain them?"

(d) "How many rooms are there in your home (apartment or house)? Do not count any separate kitchens, bathrooms, garages, balconies, hallways or cupboards."

(e) Several background questions on the household structure.

Unfortunately, the fieldwork of ISSP was delayed due to the COVID-19 crisis and the data collection is still taking place in some countries. The international dataset is now supposed to be available in 2023 and our comparison in this concluding chapter, thus, uses data from the ECHOES 
project, which also included detailed questions on climate-relevant behaviors of Europeans. The questions are slightly different than what we had developed, but are close enough to get an idea of the overall picture. ECHOES, on the other hand, doesn't include many items on environmental attitudes and concerns. Furthermore, data was collected using existing online panels, whereas ISSP allows only random samples with postal or face-to-face recruiting. Yet, the ECHOES data allow us to test our assumptions at a basic level.

In Chap. 5 we concluded that the items on car usage, beef and lamb consumption, number of flights per year, the living space in square meters, as well as the number of household members are able to account for more than three quarters of the greenhouse gas (GHG) emissions. We used the most similar items from the ECHOES project and ran a regression for each country and noted the explained variance. Fig. 8.1 shows which percentage of the variance can be explained using the items "Q8_number_residents," "Q75_km_driver," "Q92_flights_private," “Q95_dwelling_size," and "Q106_diet" plus the question "Q104_green_provider," which asks whether or not the energy provider is a green provider. This question increased the explained variance by around ten percentage points for the majority of countries. Hence, this question could be a valuable addition to an international comparative survey in the European context.

We also tried to find out, which country-level characteristics are associated with a high level of explained variance. A correlation analysis at the aggregate level suggests the explanation is higher in countries which are more affluent $(r=0.29)$, have a larger share of green parties $(r=0.36)$, and where the public is more willing to make sacrifices for the environment $(\mathrm{r}=0.42)$. Our instrument, hence, seems to be better applicable in more affluent societies and societies in which environmentalism is more widespread. Our instrument, thus, seems to be well suited to account for the GHG emissions in those societies and in those social groups that produce the most emissions. The UNEP emission report (2020) highlights that the top $1 \%$ of income earners produce around $15 \%$ of the emissions, and the top $10 \%$ of income earners (including the $1 \%$ ) produce $48 \%$ of the emissions. These groups are well captured in the ECHOES survey. The ISSP data then will show if and how strongly the emissions-relevant behaviors also differ within developing countries. 


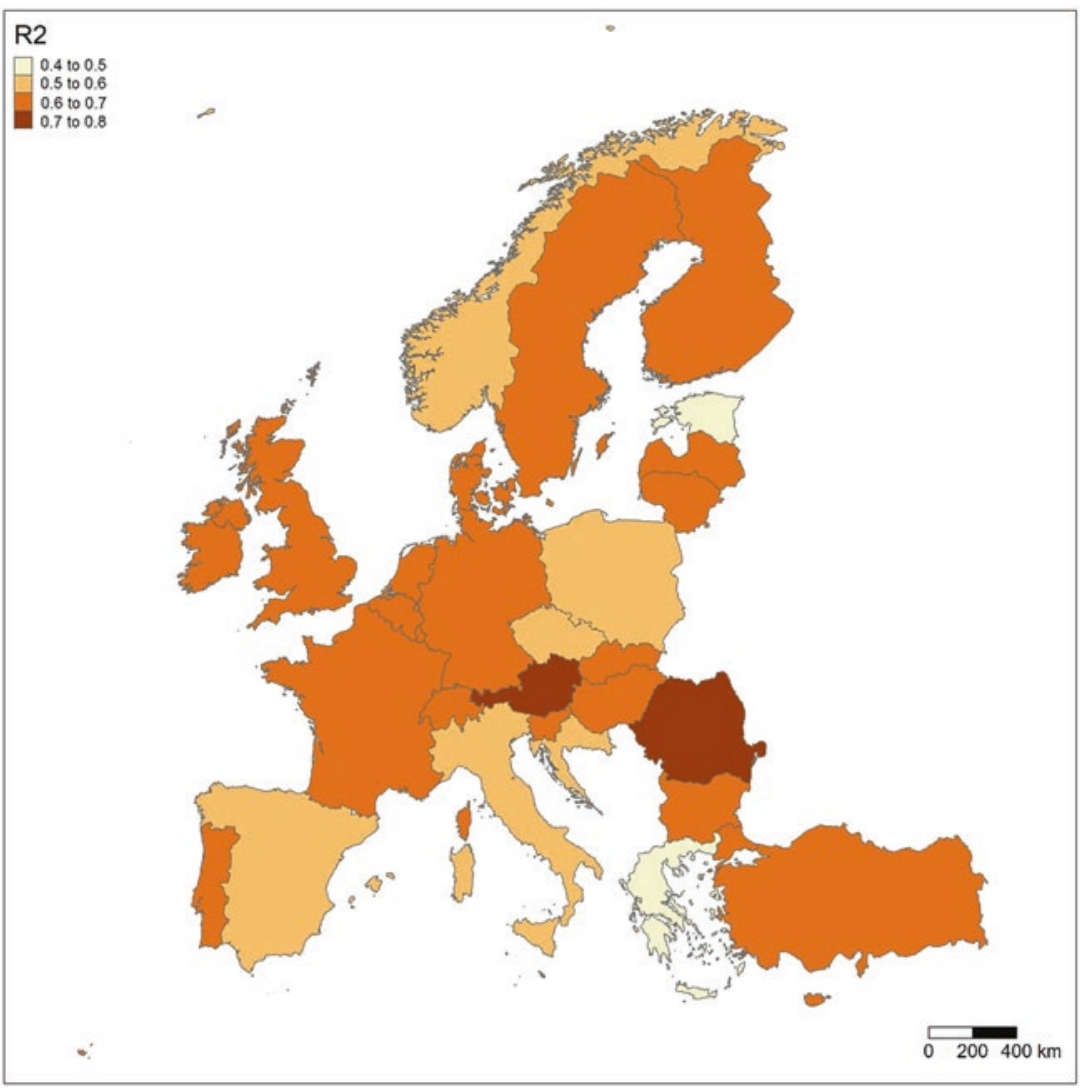

Fig. 8.1 Explained variance of total GHG emissions. Explained variance $\left(\mathrm{r}^{2}\right)$ in regression with "Q8_number_residents," "Q75_km_driver," "Q92_flights_private," “Q95_dwelling_size," "Q106_diet," and "Q104_green_provider" as independent variables. (Source: Calculation by DN Bird based on ECHOES data [Reichl et al., 2019])

\subsection{LifESTYLES IN AN INTERNATIONAL ViEW}

Chapter 6 showed that the Austrian population can be clustered into five distinctive groups based on their energy demand. Using data from the ECHOES project, we now test whether these groups can also be found when using GHG emissions instead of the energy demand and, if so, how 
large they are in other European countries. Subsequently, we look into the factors that shape their occurrence. These analyses, however, are limited to the country level and thus rest on a maximum of 31 observations.

The analyses based on GHG emissions result in one to two additional lifestyle groups depending on the clustering criteria used. These additional groups are a cluster of "averages" and a cluster with "low consumption in food." For the sake of comparability to Chap. 6, we use only the four groups in this international outlook, which occur in both analyses, that is, in the GHG emission and the energy demand approach. Furthermore, we omit the group with a high demand in leisure and information from Chap. 6 , as this group splits into new groups when changing to a GHG approach.

The four lifestyles we consider in detail are Homers, Travelers, Savers, and Consumers. Homers are characterized by high consumption in the area of housing, Travelers by high mobility in terms of car usage and air travel, and Consumers by high goods usage. Savers is the group that is below average in all categories. Figure 8.2 provides an overview of their prevalence in different European countries. It shows that Savers and Travelers are more common than Homers and Consumers in all countries. The former groups reach a prevalence of more than $30 \%$ of the population in some countries, whereas Consumers are commonly around $10 \%$ and Homers often below this figure. Furthermore, the occurrences of Consumers and Savers are negatively correlated, indicating that they represent opposed patterns.

Alongside the prevalence of these lifestyles, we also consider the factors that shape their extend and occurrence. The literature points to an association between environmental impact and affluence, population, attitudes, environmental state, and political factors as pointed out in Chap. 2. We hence correlated the size of the lifestyle clusters in the European countries with related country characteristics. In particular, we included the level of affluence (GDP per capita) and human development (HDI), population density (people per square $\mathrm{km}$ ), age structure (\% of population above 65 years) and urbanization (\% of the population living in cities), the state of the environment in terms of water quality, GHG emission per capita, biomass available per capita; environmental attitudes and concerns in terms of percentage of the population that worries about the climate and their willingness to do something for the environment, as well as political factors such as the comparative magnitude of the green party in the last national election, expenditures on environmental protection (\% of GDP), and the protected land areas ( $\%$ of total area). Finally, we also considered 

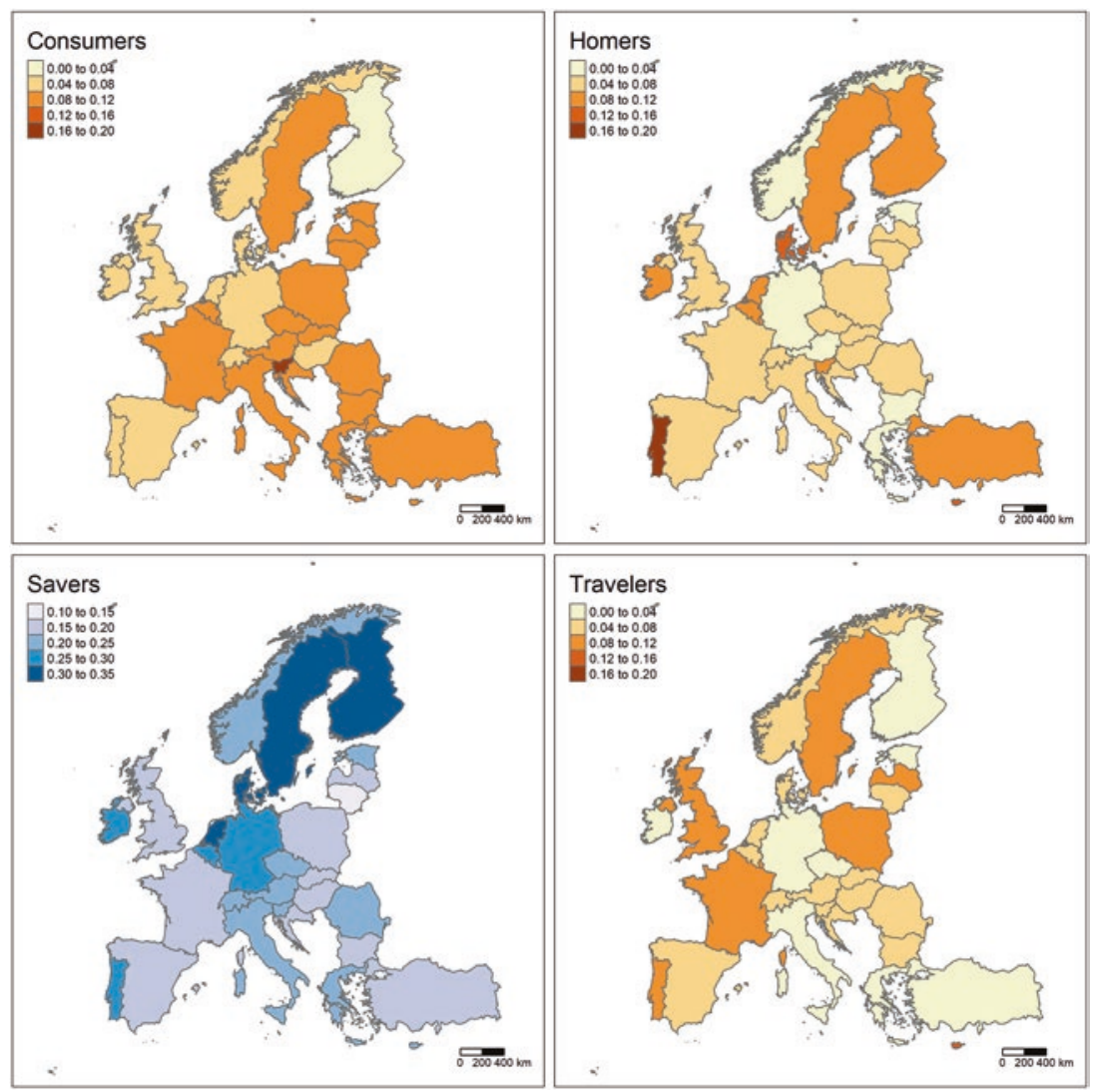

Fig. 8.2 Lifestyles across Europe. (Source: Calculation by DN Bird based on ECHOES data [Reichl et al., 2019])

the mobility indicators "cars per 1000 people" and "railroad km per head." Data were derived from Eurostat, the European Social Survey, the Manifesto Project, OECD, UNDP, the World Bank, and the Yale Environmental Performance Index.

Considering the correlation between these indicators and the frequency of the lifestyles shows that indicators of development are positively correlated with the frequency of Savers and negatively with Consumers, whereas there are only very weak and inconsistent associations with the percent of Homers and Travelers. Demographic factors have the strongest effects on 
Homers. Homers are more common in densely populated and more urban countries. The state of the environment in terms of GHG per capita, the available biomass per capita, water quality, and so on do not show any strong correlation with the exception of available biomass, which is correlated with Consumers and somewhat with Travelers. There is, however, no obvious substantive interpretation for this correlation. ${ }^{2}$ Worries about the climate are associated with a large number of Homers and the readiness to make sacrifices for the environment is correlated with the frequency of Savers. As for the political institutionalization of environmental topics, larger shares of green parties are associated with fewer Consumers, higher expenditures on environmental measures with larger shares of Savers, and the percentage of protected areas of land with a larger number of Consumers.

Interpreting these associations from a lifestyle view shows that Consumers are more common in countries that are less affluent, and have a lower environmental performance and a less influential green party. In the Austrian context of Chap. 6, this group was characterized by buying lots of fashion and electronics - in other words expressing a more materialistic lifestyle. Using Inglehart's view on the development of postmaterialism, we would have indeed expected to find them more often in less affluent countries. The findings at the micro-level and the international outlook are thus in line. The Homers can be found in dense and urban countries in our international outlook. In the Austrian context, the analysis shows a trend toward single-person and smaller households and older respondents. There is however no correlation between age structure and this lifestyle in the European context. This lifestyle, hence, seems to be more common with ongoing aging and urbanization within and between countries. Again, the micro-level interpretation and the international outlook are mostly aligned. The picture is more complex as far as Savers are concerned. This lifestyle is more common in affluent countries and societies where the willingness to make sacrifices is high and environmental protection is well established. Interestingly, this group was characterized by lower status and limited labor market integration within the Austrian context. The national finding and the international outlook lead to opposite interpretations. Travelers, finally, are not linked to any specific societal characteristics considered so far. The national finding was that

\footnotetext{
${ }^{2}$ Land use and biomass are also associated with high unemployment and lower affluence. Hence, the associations between land use/biomass and lifestyles might be spurious.
} 
men and better educated individuals are typical for this group. There is a positive correlation between rail passengers (per head) and Travelers, but not with cars per 1000 inhabitants. The latter, however, is correlated with the frequency of Savers (probably due to development correlation).

\subsection{COVID-19 CRISIS AND IMPACT}

As pointed out in the introduction, the advent of the COVID-19 crisis brought a sudden end to the attention given to the climate crisis. Yet, the restrictions imposed by the different governments to address the COVID-19 crisis led to a reduction in GHG emissions. The UNEP (2020) emissions report shows in this regard that the emissions dropped significantly in the areas of ground transportation, power, industry, and aviation. These reductions, however, occurred due to a mandated change and were not based on the voluntary behavioral changes of individuals. It is thus unclear how the COVID-19 crisis will affect the underlying environmental attitudes and behaviors in the long run.

During the first wave of the COVID-19 crisis in 2020, Austria took part in the Values in Crisis Study (VIC, 2021), which was initiated by researchers from the World Values Survey (WVS, www.worldvaluessurvey. org). This survey includes questions from the WVS and COVID-19 related items. At the time of this publication, merged data was available for Austria, Brazil, China, Colombia, Germany, Georgia, Greece, Italy, Japan, Kazakhstan, Maldives, Poland, South Korea, Sweden, and the United Kingdom. The Austrian data (Aschauer et al., 2020) also included a question on the "willingness to make sacrifices for the environment," which according to Mayerl and Best (2019) reflects the behavioral dimension of the tripartite classification of Maloney and Ward's (Maloney \& Ward, 1973) ecology scale, is part of Dunlap and Jones' (2002) environmental concern, and can be seen as a behavioral intention variable that fits Ajzen and Fishbein's (1980) attitude-behavior model.

In the Austrian context, we were able to show that the willingness to make sacrifices for the environment in terms of paying higher prices and taxes as well as accepting reductions in the standard of living dropped during the COVID-19 crisis (Klösch et al., 2021). The international VIC dataset includes unfortunately only a single item on environmental attitudes. Respondents are asked on a 6-point scale whether the description "She/he strongly believes that people should care for nature. Looking after the environment is important to her/him" is "very much like me" to 


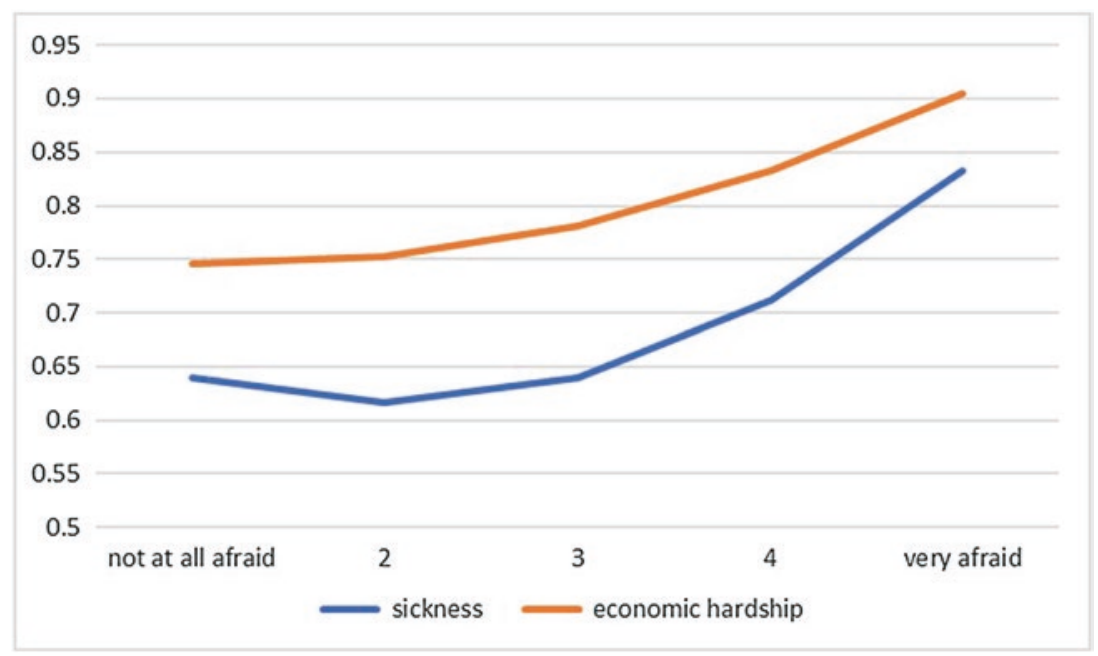

Fig. 8.3 Association between worries about economic and health impact of COVID-19 and the self-perception as person who acts for the environment. (Source: Regression using VIC [2021] data)

"not at all like me." We used this item in a regression considering education, age, income, gender, left-right scale, and country of residence as controls and worries about economic hardship and health issues due to COVID-19 as independent variables.

Figure 8.3 shows the average effects across all countries, based on the regression mentioned before. The vertical axis displays the predicted selfperception with a higher value indicating a more environmentally friendly self-perception. The horizontal axis displays the strength of the COVID-19 fears with an increasing worry from the left to the right. The relationship between worries about COVID-19 and the self-perception as an environmentalist is slightly curvilinear. Overall, respondents who are worried about COVID-19 also care about the environment. A possible interpretation is that we observe a general underlying notion of concern, which is in line with the benevolence and universalism dimension of Schwartz's value theory (2012).

These findings indicate an increasing "environmentalism" due to COVID-19 fears. Yet, the VIC question on the self-perception must not be considered equal to a measure of environmental behaviors. As pointed out before, we noticed a declining willingness to make sacrifices for the 
environment during the COVID-19 crisis in the extended Austrian dataset (Klösch et al., 2021). Furthermore, we also found that in particular respondents who are worried about the economic impact of COVID-19 are less willing to make sacrifices for the environment. ${ }^{3}$ This is not surprising, assuming that individuals who struggle economically most likely do not have the means to spend more money on the environment. The willingness item, however, is not included in the international dataset and we thus cannot test it empirically at an international comparative level. Future research will have to look into the long-term effects of the COVID-19 crisis on climate-relevant behaviors and related concerns.

\subsection{Overall Impact and Individual Actions}

So far, we have considered the measurement of GHG emissions, its international applicability, and also the effects of the COVID-19 crisis on environmental attitudes and behaviors. The most pressing questions concerning our book in terms of societal resilience is how the climate crisis can be tackled and how to reduce GHG emissions to a level that is in line with the Paris goals. We can recur to the IPAT equation (Rosa et al., 2015; Harper, 2015) for this purpose and consider the factors population "P," affluence "A," and technology "T" when assessing the factors that shape the impact "I," that is, GHG emissions in our case.

The first main factor is population size. First, the total emissions of a society depend strongly on the size of population, even when controlled for technology and affluence. In this regard, larger societies such as China and the United States emit a large amount of GHG. The 2019 figures are $14 \mathrm{GtCO}_{2} \mathrm{e}$ for China and $6.6 \mathrm{GtCO}_{2} \mathrm{e}$ for the United States (UNEP, 2020, p. 5). The size of the impact of single individuals, on the other hand, is estimated more accurately when considering the per-capita output. Here, the figures are $9.7 \mathrm{tCO}_{2} \mathrm{e}$ for China and $20.0 \mathrm{tCO}_{2} \mathrm{e}$ for the United States (ibid.). Given that the total number of emissions counts, reductions have to be particularly large in growing societies.

The second factor, affluence, points to the consumption patterns. The comparison of the per-capita GHG output in the United States and China showed that the former consumes much more per head, which points to the unequal distribution of consumption and GHG emissions. According

\footnotetext{
${ }^{3}$ Interestingly, also respondents, who did not worry at all about COVID-19, were less willing to make a sacrifice for the environment.
} 
to the UNEP (2020), the richest 10\% of the global income earners emit around $48 \%$ of the GHG and the poorest $50 \%$ only $7 \%$ of all GHG. To balance increasing development, population growth, affluence, associated increasing emissions, and the overall need to reduce the total emissions of GHG evokes questions of social justice and fairness. Is it, for example, right to demand that developing societies not become more affluent, so that the affluent societies have to change less? We doubt it.

Technology, the third factor, refers to production processes and also to the combustion material used. Theories on ecological modernization proposed that the impact would be smaller once technology advances. Results, however, are mixed (Harper, 2015). As for climate change, ideas such as GHG storage, shielding the planet from sun rays are the most extreme ideas. More realistically, the replacement of fossil fuels by renewable energy sources, such as oil-based heating systems with heat pumps or hydrogen instead of petrol, is plausible. Yet, we can run into a Jevon's problem in the sense that an increasing use of materials offsets the increase in efficiency, which is also related to the previous paragraphs on population growth and increasing affluence for large parts of the world's population.

The IPAT formula offers a broad overview of the different dimensions, but does not aim to provide any specific guidelines and ideas for individuals. The current UNEP emission report includes an entire chapter that focuses on how to shape individual action (UNEO, 2020, pp. 70-73). It distinguishes between (a) the social and contextual circumstances such as media, social norms, social movements, and so on; (b) structural circumstances such as policies, infrastructures, supply chains, and others; and (c) personal and immediate circumstances such as knowledge, attitudes, habits, and so on. All of these three circumstances shape lifestyles and, in turn, lifestyles and actions of individuals also shape these circumstances.

Using these divisions as a backdrop, the UNEP report highlights a few mechanisms that may change behaviors. It points out that, first, incentives, information, and choice provision do work to a certain extent, but larger sustainable change can occur only by changing social norms and the options available (UNEP, 2020, p. 71). Restrictions and laws also work well, but depend on the acceptance by the population. Second, the available infrastructure can be addressed. Here, the availability of public transport and suburbanization, and so on play a role. Third, social influence, in the sense that a single person can influence their social environment, is mentioned. Installing a photovoltaic system on a house, for example, might entice other neighbors to do the same, initiating social change. 
Fourth, citizen participation in social movements and inclusion in politics also empowers individuals and might increase the likelihood of changing to more climate-friendly behaviors. Finally, the report also points to disrupting habits - to challenge routine behaviors. The latter occurred prominently during the COVID-19 crisis.

The findings presented in this book are related to these points. Chapter 5 showed that the total GHG emissions of our respondents are related to their place of residency, that is, urban, suburban or rural, income, and age. These findings are similar to previous studies which found a strong influence of these factors on consumption (Poortinga et al., 2004). As for attitudes and concerns, the willingness to make sacrifices for the environment had significant effects, whereas attitudes such as fatalism were not significant. Of course, we need to bear in mind that our analysis remained at an overall level and that attitudes might become significant, when comparing individuals in similar life circumstances. Furthermore, previous studies already pointed out that the effects of attitudes are stronger on the intention to change behaviors (Abrahamse \& Steg, 2009). Overall, this first analysis underscored the influence of the context and hence points to infrastructural measures as a lever for change.

The subsequent chapter considered the different lifestyles of individuals and their energy consumption in six different areas of social life (see also Schwarzinger, Bird, \& Hadler, 2019a, Schwarzinger, Bird, \& Skjølsvold, $2019 b)$. The lifestyles of Travelers and Homers turned out to use the most energy of all groups. Considering these two areas, policy measures aiming at an effective reduction of energy demand will have to look into replacing fossil fuels, increasing the efficiency of heating systems and means of transportation, or into altering behaviors. The climate crisis, however, cannot be solved only by considering these groups. Firstly, they are rather small in size. Secondly, even the group with the lowest consumption - the Saversis exceeding the allotted GHG emissions by far. Policy measures, thus, need to target even very frugal Consumers in the Western societies.

Chapter 7 considered the perceived obstacles to act in an environmentally sound way. The interviewees frequently mentioned a lack of information and pointed to the limited choices in goods and public transportation, especially in the rural areas. The presence of a willingness to do something is bound by the options. Interviewees suggested changes at the structural and political level, that is, that a change in market regulation is desired, especially with regard to offering and promotion of eco-friendly alternatives, but also pointed to increasing education, information dissemination, 
and awareness raising among the population in order to counteract intrapersonal barriers. These suggestions are also in line with findings from the "Model of Pro-Environmental Behavior" by Kollmuss and Agyeman (2002), that is, the importance of structural conditions as well as routines and habits for pro-environmental behavior, and with the importance of situational factors in Barr's "Framework of Environmental Behavior" (Barr, 2004, 2006). However, we also need to consider that certain decisions lie outside of routine actions, such as buying a car or moving to a larger place. Here, zoning and policies that limit choices might be advantageous as well.

\subsection{CONCLUding Remarks}

Our book started with the idea of developing a survey that allows researchers to measure a respondent's greenhouse gas emissions in a concise manner. We were successful in the sense that we were able to identify a few questions on mobility, housing, and diet that are able to account for more than three quarters of a respondent's emissions. While these three areas were known beforehand as GHG-intensive areas, the specific contribution is that we offer survey researchers specific guidance on this task. Furthermore, while focusing initially on Austria, we were able to show that these items also work in other European countries.

In terms of explaining the GHG of respondents, we confirmed, on the one hand, that the standard models of environmental behavior apply and that the overall GHG output is heavily influenced by context, situational variables, and socio-demographics. Our analyses, however, pointed to several new directions that need to be considered. First, we identified specific lifestyles and patterns of consumption that showed that some social groups have a strong impact in only one or two areas and that some respondents are below average in all areas. Climate policies need to consider these specific patterns. Second, we also showed that the use of multiple methods and data sources allow for a more holistic picture. The initial analysis was based on a survey. Based on the information derived from this survey, qualitative interviews were conducted with individuals who show a gap between their attitudes and behaviors. Our next step, then, will be to extend our analyses beyond the European context. Finally, our different analyses and findings showed that there is need for a variety of different support measures and options in order to facilitate climate-friendly behaviors. Yet, we must not forget that there are also other social and environmental problems that need to be addressed at the same time. 


\section{REFERENCES}

Abrahamse, W., \& Steg, L. (2009). How do socio-demographic and psychological factors relate to households' direct and indirect energy use and savings? Journal of Economic Psychology, 30(5), 711-720.

Ajzen, I., \& Fishbein, M. (1980). Understanding attitudes and predicting social behavior. Prentice-Hall.

Aschauer, W., Seymer, A., Prandner, D., Baisch, B., Hadler, M., Höllinger, F., \& Bacher, J. (2020). Values in crisis Austria (SUF edition). Retrieved January 11, 2021, from https://doi.org/10.11587/H0UJNT, AUSSDA, Vl, UNF:6:FkbXIWYV0relMqlAelICTA== [fileUNF].

Barr, S. (2004). Are we all environmentalists now? Rhetoric and reality in environmental action. Geoforum, 35, 231-249.

Barr, S. (2006). Environmental action in the home: Investigating the 'valueaction' gap. Geography, 91(1), 43-54.

Dunlap, R. E., \& Jones, R. E. (2002). Environmental concern: Conceptual and measurement issues. Handbook of Environmental Sociology, 3(6), 482-524.

Harper, C. (2015). Environment and society: Human perspectives on environmental issues (2-downloads). Routledge.

Klösch, B., Wardana, R., \& Hadler M. (2021). The negative impact of the COVID-19 crisis on the willingness to act for the environment. Results from a survey of Austrians during the COVID-19 pandemic. Unpublished manuscript.

Kollmuss, A., \& Agyeman, J. (2002). Mind the gap: Why do people act environmentally and what are the barriers to pro-environmental behavior? Environmental Education Research, 8(3), 239-260.

Maloney, M. P., \& Ward, M. P. (1973). Ecology: Let's hear from the people: An objective scale for the measurement of ecological attitudes and knowledge. American Psychologist, 28(7), 583-586. https://doi.org/10.1037/h0034936

Mayerl, J., \& Best, H. (2019). Attitudes and behavioral intentions to protect the environment: How consistent is the structure of environmental concern in cross-national comparison? International Journal of Sociology, 49(1), 27-52.

Poortinga, W., Steg, L., \& Vlek, C. (2004). Values, environmental concern, and environmental behavior: A study into household energy use. Environment and Behavior, 36(1), 70-93. https://doi.org/10.1177/0013916503251466

Reichl, J., Cohen, J., Kollmann, A., Azarova, V., Klöckner, C., Royrvik, J., Vesely, S., Carrus, G., Panno, A., Tiberio, L., Fritsche, I., Masson, T., Chokrai, P., Lettmayer, G., Schwarzinger, S., \& Bird, N. (2019). International survey of the ECHOES project. Dataset. Zenodo. https://doi.org/10.5281/ zenodo. 3524917

Rosa, E. A., Rudel, T. K., York, R., Jorgenson, A. K., \& Dietz, T. (2015). The human (anthropogenic) driving forces of global climate change. Climate Change and Society: Sociological Perspectives, 2, 32-60. 
Schwartz, S. H. (2012). An overview of the Schwartz theory of basic values. Online Readings in Psychology and Culture, 2(1), 2307-0919. https://doi. org/10.9707/2307-0919.1116

Schwarzinger, S., Bird, D. N., \& Hadler, M. (2019a). The 'Paris lifestyle'Bridging the gap between science and communication by analysing and quantifying the role of target groups for climate change mitigation and adaptation: An interdisciplinary approach. In Addressing the challenges in communicating climate change across various audiences (pp. 375-397). Springer.

Schwarzinger, S., Bird, D. N., \& Skjølsvold, T. M. (2019b). Identifying consumer lifestyles through their energy impacts: Transforming social science data into policy-relevant group-level knowledge. Sustainability, 11(21), 6162.

United Nations Environment Programme. (2020). Emissions gap report 2020. Nairobi. https://www.unep.org/emissions-gap-report-2020

VIC. (2021). Values in crisis survey. Initiated by C. Welzel, K. Boehnke, J. Delhey, F. Deutsch, J. Eichhorn, \& U. Kühnen. https://www.worldvaluessurvey.org/ WVSNewsShow.jsp? ID $=416 \& I D=416$

Open Access This chapter is licensed under the terms of the Creative Commons Attribution 4.0 International License (http://creativecommons.org/licenses/ by $/ 4.0 /$ ), which permits use, sharing, adaptation, distribution and reproduction in any medium or format, as long as you give appropriate credit to the original author(s) and the source, provide a link to the Creative Commons licence and indicate if changes were made.

The images or other third party material in this chapter are included in the chapter's Creative Commons licence, unless indicated otherwise in a credit line to the material. If material is not included in the chapter's Creative Commons licence and your intended use is not permitted by statutory regulation or exceeds the permitted use, you will need to obtain permission directly from the copyright holder.

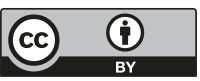

